\title{
Adverse Drug Reaction Policy in a Tertiary Care Hospital
}

\author{
${ }^{1} \mathrm{~S}$ Singh, ${ }^{2}$ Shakti Kumar Gupta, ${ }^{3} \mathrm{~S}$ Arya, ${ }^{4} \mathrm{DK}$ Sharma, ${ }^{5} \mathrm{~V}$ Aggarwal
}

\begin{abstract}
Adverse drug reactions (ADRs) are a significant cause of morbidity and mortality and contribute to the incidence of adverse events, resulting in increased healthcare costs. Healthcare providers need to understand their role and responsibility in the detection, management, documentation, and reporting of ADRs. The purpose of this study is to provide guidelines regarding the procedure of reporting ADRs to hospital authority. It was a descriptive cross-sectional study carried out between April and August 2013. The study population included doctors, nursing personnel, paramedical staff and quality managers of tertiary care hospital from one public and two private hospitals. Interaction was done with study population against the back drop of the checklist and ADR policy was formulated.
\end{abstract}

Keywords: Adverse drug reactions, Adverse drug event, Medication error, Near-miss, Drug-related side effects.

How to cite this article: Singh S, Gupta SK, Arya S, Sharma DK, Aggarwal V. Adverse Drug Reaction Policy in a Tertiary Care Hospital. Int J Res Foundation Hosp Healthc Adm 2015; 3(1):41-47.

Source of support: Nil

Conflict of interest: None

\section{INTRODUCTION}

\section{Review of Literature}

Safety issues arise whenever medical choices have to be made. ${ }^{1}$ Adverse drug reactions (ADRs) can occur in all settings where healthcare is provided. Most of the current evidence comes from hospitals, because the risks associated with hospital treatment are higher. ${ }^{2}$ Drug manufacturing process has been revolutionized by modern techniques, drug safety assessment stays behind and is still

\footnotetext{
${ }^{1}$ Senior Resident, ${ }^{2,4}$ Medical Superintendent, ${ }^{3}$ Professor ${ }^{5}$ General Manager

1,3,4 Department of Hospital Administration, All India Institute of Medical Sciences, New Delhi, India

${ }^{2}$ Department of Hospital Administration, Dr RPCOS, All India Institute of Medical Sciences, New Delhi, India

${ }^{5}$ Department of Hospital Administration, Max Hospital, New Delhi, India
}

Corresponding Author: S Singh, Senior Resident, Department of Hospital Administration, All India Institute of Medical Sciences, New Delhi, India, e-mail: sheetalsingh2003@ hotmail.com reliant on technologies that have been used for several decades. Current conceptual thinking on the safety of patients places the prime responsibility for ADRs on deficiencies in system design, organization and operation - rather than on individual practitioners or products. ${ }^{3}$

According to the World Health Organization definition, ADR is any noxious, unintended, and undesired effect of a drug, which occurs at doses used in humans for prophylaxis, diagnosis, or therapy. This definition excludes therapeutic failures, intentional and accidental poisoning (i.e. overdose), and drug abuse. Also, this does not include adverse events due to errors in drug administration or noncompliance (taking more or less of a drug than the prescribed amount). Using this conservative definition avoids overestimating the ADR incidence.

\section{Types of Adverse Drug Reactions ${ }^{4}$}

Type-A (Augmented): Commonest (up to 70\%) - Dose dependent, severity increases with dose. Preventable in most part by slow introduction of low dosages. Predictable by the pharmacological mechanisms, e.g. hypotension by beta-blockers, hypoglycemia caused by insulins or oral hypoglycemics, or NSAID induced gastric ulcers.

Type-B (Bizarre): Rare, idiosyncratic, genetically determined, unpredictable, mechanisms are unknown, serious, can be fatal; unrelated to the dose, e.g. hepatitis caused by halothane, aplastic anemia caused by chloramphenicol, neuroleptic malignant syndrome caused by some anesthetics and antipsychotics.

Type-C (Continuous drug use): Occurs as a result of continuous drug use. May be irreversible, unexpected, unpredictable, e.g. tardive dyskinesias by antipsychotics, dementia by anticholinergic medications.

Type-D (Delayed): Delayed occurrence of ADRs, even after the cessation of treatment, e.g. corneal opacities after thioridazine, ophthalmopathy after chloroquine, or pulmonary/peritoneal fibrosis by methyserzide.

Type-E (End of dose): Withdrawal reactions occur typically with the depressant drugs, e.g. hypertension and restlessness in opiate abstainer, seizures on alcohol or benzodiazepines withdrawal; first dose hypotension caused by alpha-blockers (Prazosin) or ACE inhibitors.

Type-F (Failure of therapy): Results from the ineffective treatment (previously excluded from analysis according to WHO definition), e.g. accelerated hypertension because of inefficient control. 
What is adverse event ( $A E$ ): Any injury related to medical management, in contrast to a complication of disease. Medical management, includes all aspects of care, including diagnosis and treatment, failure to diagnose or treat, or failure of systems or equipment used to deliver care. ${ }^{5}$

What is adverse drug event ( $A D E$ ): The FDA recognizes the term adverse drug event to be a synonym for adverse event. In the patient-safety literature, the terms adverse drug event and adverse event usually denote a casual association between the drug and the event, but there is a wide spectrum of definitions for these terms, including harm caused by a

- Drug

- Harm caused by drug use and

- A medication error with or without harm.

An ADE, the most common type of adverse event, ${ }^{6}$ is an injury resulting from medical intervention related to a drug. ${ }^{6}$ Examples of adverse drug events include wrong dose, wrong choice, wrong drug, wrong technique, equipment failure, etc. The Harvard Medical Practice study documented that ADE accounted for $19.4 \%$ of all disabling adverse events in hospital settings with the advancement of technology and increased number of prescription drugs, the risk of adverse drug events is likely to increase. In one of the study by Brennan TA et al in 2004 it was found that of the $3.7 \%$ of hospitalized patients who experienced adverse events, $70.5 \%$ suffered disability lasting fewer than 6 months, 2.6\% suffered permanent disability and $13.6 \%$ died as a result. ${ }^{7}$

What is potential adverse drug event/'near-miss' or 'close call': Serious medication error or mishap that has the potential to cause an ADE, but fails to do so because of chance or because it is intercepted before it reaches to the patient is called potential adverse drug events/near miss.

Near misses often go underreported. There are approximately seven times as many near misses as adverse events ${ }^{6}$ patient safety encompasses the processes that protect patients from injury caused by medical mismanagement. Ensuring patient safety requires operational systems and processes that will maximize the likelihood of preventing adverse medical events.Two other terms frequently found in literature on patient safety and adverse events are nosocomial (originated in hospital) and iatrogenic (unintended and unwanted, as a result of treatment).

\section{ADVERSE DRUG REACTION POLICY IN A TERTIARY CARE HOSPITAL}

Successfully preventing adverse events relies on comprehensive and systematic data collection and analysis. In one of the Canadian study in 2001 by Orser BA et al, anesthesiology revealed that among surveyed anesthesiologists none of the adverse events described in the survey were reported to a national or a provincial body because $68.3 \%$ of participants considered those events inconsequential moreover healthcare workers were uncertain whether and how to report near misses or intercepted potential errors. ${ }^{8}$

\section{NEED OF THE STUDY}

Adverse drug reactions are one of the leading causes of morbidity and mortality in healthcare. The Institute of Medicine, in the United States (US) (2000) reported that between 44,000 and 98,000 deaths occur annually from medical errors. Of this total, an estimated 7000 deaths occur due to ASRs. Analyzing 39 studies of the American pharmaceutical system over 4 decades found that in 1994, 106,000 people died as a result of ADRs. More than 2 million suffered serious side effects. ${ }^{9}$ These figures showed that there was a trend of increasing death and injury from ADRs. That would make ADRs the fourth leading cause of death in the US behind heart disease, cancer and strokes. ${ }^{10}$ Adverse drug reactions are a significant public health problem in the world. Not only do ADRs cause death and injury but they also affect the length of stay in hospitals which in turn leads to increased healthcare costs and decreased patient productivity. In one of the study done in the year 2009 by Moura et al frequency of ADRs in intensive care units was determined and effect on the length of stay was evaluated. It was found out that each ADR presented by the patient was related to an increase of 2.38 days in the ICU. ${ }^{11}$ The quantum of ADR in our country (India) is not clear because of lack of reliable and validated data. Many steps have been taken in this regard by government and private sectors. Hence, the need for the conduct of this study is justified.

\section{MATERIALS AND METHODS}

It was a descriptive cross-sectional study carried out between April and August 2013. The study population included doctors, nursing personnel, paramedical staff and quality managers of tertiary care hospital from one public and two private hospitals. Check list was made after an exhaustive review of literature which was then improvised. Validation of the checklist was done by experts in quality assurance from NABH accredited private hospitals. Subsequently, interaction was done with study population against the back drop of the check list and ADR policy was formulated.

\section{Analysis and Results}

One hundred people which included doctors, nurses, paramedical staff, pharmacists and quality managers 
of tertiary care public and private hospitals were approached for interaction against the back drop of the check list. Total response rate was $64 \%$. Ten doctors responded out of 20 doctors approached, 16 nurses responded out of 20, 16 quality managers interacted out of 20 and 12 paramedical responded out of 20 approached and 10 pharmacist responded out of 20 approached. Policy was framed after incorporating inputs from responses received against the back drop of the check list.

\section{ADVERSE DRUG REACTION POLICY FOR A TERTIARY CARE HOSPITAL}

\section{Purpose}

- To bring awareness among healthcare providers regarding advantages of documenting and reporting ADRs.

- To define the role of pharmacist, clinicians, nursing staff and pharmacy and therapeutics committee in ADRs.

- To provide guidelines regarding the indications and procedure of reporting ADRs to hospital authority and National Pharmacovigilance System.

\section{Scope}

- All patient care areas of the hospital.

\section{Responsibility}

- All physicians

- Nursing

- Clinical pharmacist

- Pharmacy and therapeutics committee.

\section{Policy and Procedures of Reporting Adverse Drug Events/Adverse Drug Reactions}

Healthcare organizations or individuals benefit from reporting incidents if they receive back useful information gained by generalizing and analyzing the event. The policy on reporting ADE/ADR should be based on the following concepts: ${ }^{5}$

- The fundamental role of reporting systems is to enhance patient safety by learning from failures of the healthcare system.

- Individuals who report incidents must not be punished or suffer other ill-effects from reporting.

- Reporting is only of value if it leads to a constructive response. At a minimum, this entails feedback of findings from data analysis. Ideally, it also includes recommendations for changes in processes and systems of healthcare.

- Meaningful analysis, learning, and dissemination of lessons learned requires expertise and other human and financial resources. The agency that receives reports must be capable of disseminating information, making recommendations for changes, and informing the development of solutions.

Documentation of allergies/idiosyncrasy/previous $A D R-a$ measure of preventing ADR: A history of any known drug allergies/idiosyncrasies or previous ADR should be obtained during admission by the clinician as part of the initial medical assessment which should be documented in history and physical record form in the specified location for allergies. A history of any known drug allergies or previous ADRs should be obtained during admission by the staff nurse also as part of the initial nursing assessment which should be documented in the initial nursing assessment form in the specified location for allergies. Documentation should also be done, by the clinician/ staff nurse in-patient medication chart regarding drug allergies in Red Ink. For such allergic patients, there should be a red colored wrist band with the name of the particular drug. The wrist band/tag should be checked at all times before administration of medications.

\section{Documentation of Suspected ADRs}

It is not always possible to confirm that the ADR has been caused by a particular drug which needs further analysis by clinicians, pharmacist and staff nurse. Documentation should be done to facilitate the required future analysis and prevent further harm to the same patient due the use of the same drug.

\section{Which Adverse Drug Reactions should be Documented?}

As a policy directive, 'All ADRs that have caused harm or altered therapeutic care and/or where future use of the drug might cause danger or harm to a patient', should be documented.

\section{Where should be ADRs Documented?}

Adverse drug reactions should be documented in the following documents of the medical record.

Progress note: By the clinicians.

In-patient medication chart: by the clinician/staff nurses.

Nursing notes: By the staff nurses.

Red colored wrist bands: By the staff nurses.

Discharge summary: By the clinicians.

\section{Suspected Adverse Drug Reactions to be Reported to Hospital Authority}

Adverse drug reaction reporting initiates internal ADR analysis process by the clinician, pharmacist and staff nurse to confirm the relationship between the drug and the adverse effect. 
Adverse drug reaction reporting often discovers defective pharmaceutical product, supplied by manufacturer or distributor which might have caused ADRs in a number of patients.

To identify a medication error which might have caused the ADR (for preventable ADRs).

\section{Why Adverse Drug Reactions should be Repor- ted to National Pharmacovigilance System?}

The Pharmacovigilance Program of India (PVPI) was launched with a broad objective to safe guard the health of 1.27 billion people of India. Adverse drug reactions are reported from all over the country to NCC-PVPI, which also work in collaboration with the global ADR monitoring centre (WHO-UMC), Sweden to contribute in the global ADRs data base. National coordinating centre-PVPI monitors the ADRs among Indian population and helps the regulatory authority of India [Central Drugs Standard Control Organization (CDSCO)] in taking decision for safe use of medicines.

Hospital, through its authorized representative, provides the adverse reaction data to National Pharmacovigilance System as per 'National Pharmacovigilance Protocol' of Ministry of Health and Family Welfare, Government of India.

Framework for pharmacovigilance in India: The CDSCO, New Delhi, under the aegis of Ministry of Health and Family Welfare, Government of India has initiated a nation-wide pharmacovigilance programme in July, 2010, with the All India Institute of Medical Sciences (AIIMS), New Delhi as the national coordinating centre (NCC) for monitoring ADR in the country to safe-guard Public Health. In year 2010, 22 Adverse Drug Reactions monitoring centers (AMCs) including AIIMS, New Delhi had been set up under this program.

To ensure implementation of this program in a more effective way, the NCC was then shifted from the All India Institute of Medical Sciences (AIIMS), New Delhi to the Indian Pharmacopoeia Commission (IPC), Ghaziabad, (UP) in April, 2011.

\section{Function of the National Pharmacovigilance Centre Based at CDSCO}

It monitors the adverse drug reactions of medicines in order to identify previously unexpected ADRs or indicate that certain reactions occur more commonly than previously believed. This includes the collation, review and evaluation of all spontaneous ADR reports received by the unit on a nation-wide basis. This information is then keyed into the ADR database for use in aggregate analysis. These reports are also submitted to the WHO International Drug Monitoring Programme for international collaboration on drug safety.

\section{Procedures for Reporting Adverse Drug Reactions to the Hospital Authority}

- Staff nurse who identifies an ADR should immediately inform the on duty doctor.

- Staff nurse should also assess the patient and if the event is significant or with the potential to cause patient harm, should provide immediate care to the patient.

- Staff nurse should be aware of ADRs/side effects of various drugs to anticipate and monitor accordingly.

- Staff nurse should be familiar with management of various ADRs to organize treatment more efficiently.

- Staff nurse should be familiar with various precautions to avoid medication error which may also lead to ADR.

- In case of ADR, the drug should be stopped immediately and the doctor after evaluating the patient should advice the treatment as appropriate.

- The staff nurse should provide the treatment as per directive from the doctor.

- The doctor reports the ADR to the consultant immediately and obtains his advice.

- The on duty doctor should also inform the administrator/coordinator.

- The staff nurse should inform the ADR to the senior nurse immediately.

- The patient should be monitored continuously either by a doctor or by a staff nurse till the patient is clinically stabilized.

- The doctor should document the events in the progress notes, staff nurse should document the events in the nursing notes.

- The ADRs should also be documented in the discharge summary.

\section{Documentation of ADR Reporting Form}

Adverse drug reaction should be reported to the hospital authority by completing the ADR reporting form (Annexure I). Nursing In-charge of the area should be responsible for providing the ADR reporting form. The form should be filled up even if it is a suspected. Documentation should also be done by the doctor in the inpatient medication chart for discontinuation of the medication and to note regarding the ADR in the specified location in In-patient medication chart for drug allergy or ADR in red ink.

\section{Procedures for Reporting Adverse Drug Reactions to National Pharmacovigilance Center}

Reporting of ADRs to National Pharmacovigilance Center is absolutely a voluntary procedure. It is neither 
Annexure I: Adverse drug reaction reporting form

Kind attention please

- Report even if you are not certain the product caused adverse reaction.

- Time duration of submitting the form should not exceed beyond 24 hours or earlier to nursing In-charge. She/He will further submit it to NS office, MS Office and Pharmacist.

- At least four copies shall be made one for NS Office, one for MS Office, one for respective department and one for pharmacist.

\begin{tabular}{lll}
\hline A. Patient details: & & \\
\hline Name & Age & Sex \\
\hline UHID & CR no. & Bed no. \\
Department & Consultant & Body weight \\
Date of admission & &
\end{tabular}

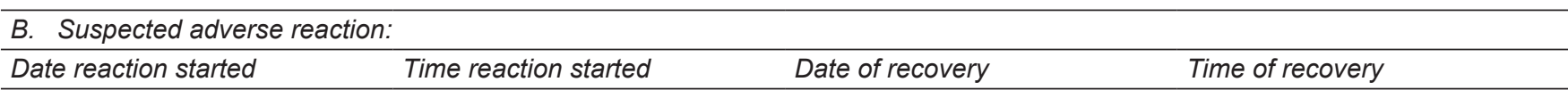

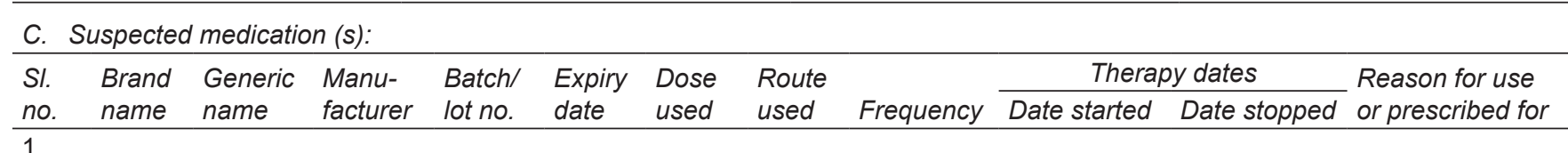

2.

3.

\begin{tabular}{|c|c|c|c|c|c|c|c|c|}
\hline $\begin{array}{l}\text { Sl. } \\
\text { no. }\end{array}$ & $\begin{array}{l}\text { Brand } \\
\text { name }\end{array}$ & $\begin{array}{l}\text { Generic } \\
\text { name }\end{array}$ & $\begin{array}{l}\text { Whether stopped } \\
\text { the doses/ } \\
\text { reduced }\end{array}$ & $\begin{array}{l}\text { Reduced doses } \\
\text { (if reduced) }\end{array}$ & $\begin{array}{l}\text { Whether } \\
\text { drug } \\
\text { reintroduced }\end{array}$ & $\begin{array}{l}\text { Date of } \\
\text { reintroduction }\end{array}$ & $\begin{array}{l}\text { Dose of } \\
\text { reintroduction }\end{array}$ & $\begin{array}{l}\text { Wheather } \\
\text { reaction reappeared } \\
\text { after reintroduction }\end{array}$ \\
\hline \multicolumn{9}{|c|}{ 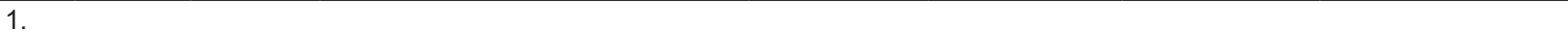 } \\
\hline \multicolumn{9}{|l|}{2.} \\
\hline \multicolumn{9}{|l|}{3.} \\
\hline \multicolumn{9}{|c|}{ E. Relevant tests/laboratory data with date } \\
\hline Date & Inves & gation & Value & Jormal range & Date & estigation & Value & Normal range \\
\hline
\end{tabular}

F. Relevant history

Allergies/idiosyncrasy/adverse drug reaction/race/pregnancy/smoking/alcohol use/hepatic dysfunction/renal dysfunction

G. Seriousness of the reaction: (yes/no)
(a) Death (with date)
(b) Life-threatening
(c) Prolonged hospitalization
(d) Disability (significant, persistent or permanent)
(e) Required intervention to prevent permanent impairment or damage
(f) Other (specify)

H. Outcome

\begin{tabular}{|c|c|c|c|}
\hline (a) Fatal & (b) Recovering & (c) Recovered & \\
\hline (d) Treatment continued & (e) Unknown & (f) Other (specify) & \\
\hline I. Signature of staff nurse & Name/employee ID & Date & Time \\
\hline J. Signature of doctor & Name/employee ID & Date & Time \\
\hline
\end{tabular}

a mandatory nor a legal requirement. It is, therefore, the What to be Reported to National
Pharmacovigilance Center?

discretion of the pharmacy and therapeutics committee

The National Pharmacovigilance Programme (NPP) to take decision regarding the ADRs which are to be reported to National Pharmacovigilance Center.

encourage reporting of all suspected drug related adverse 


\section{SUSPEGTED ADUERSE DRUG REAGTION REPORTING FORM}

\author{
CDSCO \\ Central Drugs Standard Control Organization \\ Directorate General of Health Services, \\ Ministry of Health \& Family Welfare, Government of India, \\ Nirman Bhawan. New Delhi - 110011 \\ www.cdsco.nic.in
}

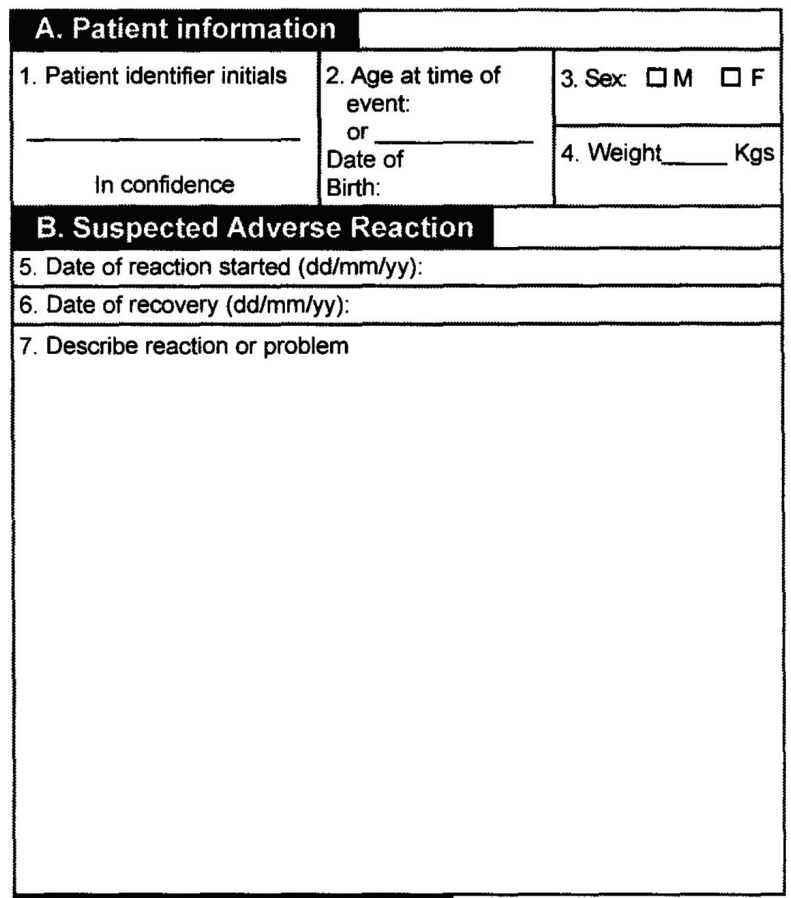

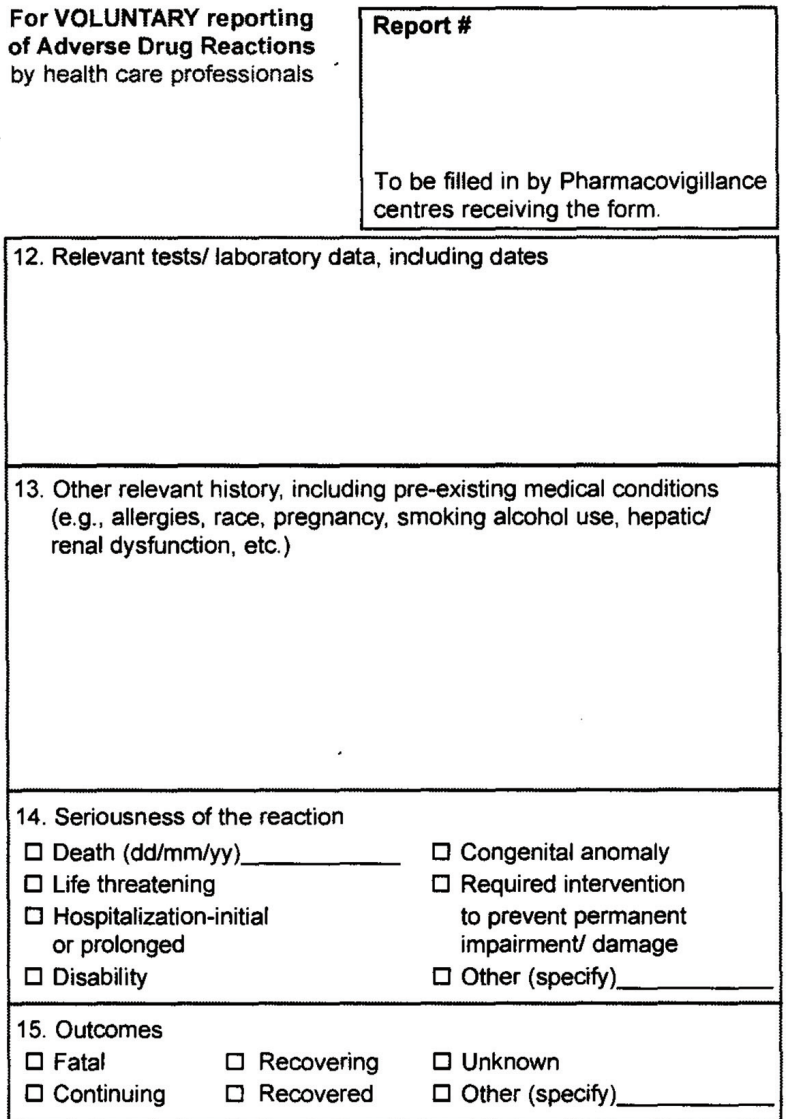

For VOLUNTARY reporting
of Adverse Drug Reactions

by health care professionals

To be filled in by Pharmacovigillance centres receiving the form.

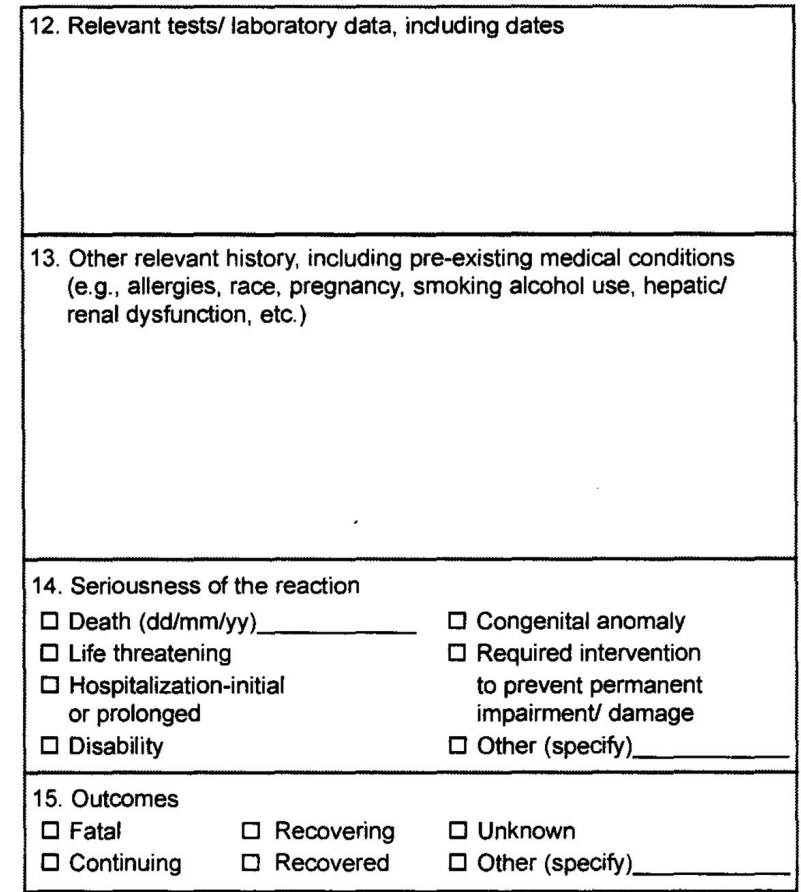


events, including those suspected to have been caused by herbal, traditional or alternative remedies

- All adverse events suspected to have been caused by new drugs and 'Drugs of current interest' (List to be published by CDSCO from time to time)

- All suspected drug interactions

- Reactions to any other drugs which are suspected of significantly affecting a patient's management, including reactions suspected of causing:

- Death

- Life-threatening (real risk of dying)

- Hospitalization (initial or prolonged)

- Disability (significant, persistent or permanent)

- Congenital anomaly

- Required intervention to prevent permanent impairment or damage.

\section{Form to be used for Reporting}

The CDSCO 'ADRs reporting form' (Annexure II) should be used for the purpose of reporting to NPP.

\section{Who can Report?}

These are among the most frequently asked questions by a novice in pharmacovigilance. Health professionals working in the field of delivering the healthcare (both conventional and unconventional) like physicians, dentists, nurses, pharmacists, can report suspected ADRs by letter, phone, fax, e-mail, or by personal contact to any of the five adverse drug reaction monitoring centers located across the country. Or the pharmacy and therapeutics committee should nominate any clinician preferably the consultant or any other clinician or the clinical pharmacist to report the ADR to National Pharmacovigilance Center.

\section{Whom to Report?}

Reporting can be done to the Pharmacovigilance Centre nearest to the reporter. (Complete list of Pharmacovigilance Centres is available at: www.cdsco. nic.in). In case of doubt, the form may be sent to the National Pharmacovigilance Centre at: Central Drugs Standard Control Organization, Directorate General of Health Services, Ministry of Health and Family Welfare, Nirman Bhawan, New Delhi 110011.

\section{What Happens to the Information Submitted?}

The information in the form should be handled in strict confidence. Peripheral Pharmacovigilance Centres shall forward the form to the respective Regional Pharmacovigilance Centres who will carry out the causality analysis. This information should be forwarded to the
Zonal Pharmacovigilance Centres. The data should be statistically analyzed and forwarded to the global pharmacovigilance database managed by WHO Uppsala Monitoring Center in Sweden. The final report based on the analyzed data should be periodically reviewed by the National Pharmacovigilance Advisory Committee constituted by the Ministry of Health and Family Welfare. The committee is entrusted with the responsibility to review data and suggest any regulatory interventions that may be required with respect to the drug/ drugs or class of drugs.

\section{What is the Procedures for Reporting Adverse Drug Reactions of Clinical Trial Patients?}

In case of clinical trial patients, it is mandatory that the serious adverse reactions are communicated to the clinical trial sponsors within 24 hours of ADR incident.

\section{REFERENCES}

1. Bauer P. Adaptive designs: looking for a needle in the haystack - a new challenge in medical research. Stat Med 2008 May 10;27(10):1565-1580.

2. Rashed AN, Wong ICK, Cranswick N, Tomlin S, Rascher W, Neubert A. Risk factors associated with adverse drug reactions in hospitalised children: international multicentre study. Eur J Clin Pharmacol [Internet]. 2012 May [cited 2015 Apr 14];68(5):801-810. Available at: http://www.ncbi.nlm.nih. gov/pubmed/22166934.

3. Alomar MJ. Factors affecting the development of adverse drug reactions (Review article). Saudi pharmaceutical journal: the official publication of the Saudi Pharmaceutical Society [Internet]. King Saud University; 2014 Apr [cited 2015 Mar 22];22(2):83-94. Available at: http://www.pubmedcentral. nih.gov/articlerender.fcgi?artid=3950535andtool=pmcen trezandrendertype $=$ abstract.

4. Dhikav V, Singh S, Anand KS. Adverse drug reaction monitoring in India. JIACM 2004;5(1):27-33.

5. WHO Draft guidelines for adverse event reporting and learning systems.

6. Bates DW, Cullen DJ, Nan Laird LAP. Incidence of adverse drug events and potential adverse drug events. JAMA 1995;274(1):29-34.

7. Brennan TA, Leape LL, Laird NM, Hebert L, Localio AR, Lawthers AG, et al. Incidence of adverse events and negligence in hospitalized. The New England Journal of Medicine 1991 Feb 7;324(6):370-376.

8. Orser BA, Chen RJ, Yee DA. Medication errors in anesthetic practice: a survey of 687 practitioners. Canad J Anaesthesia 2001 Feb;48(2):139-146. Available at: http://www.ncbi.nlm. nih.gov/pubmed/11220422.

9. Lazarou J, Pomeranz BH, Corey PNP. Incidence of adverse drug reactions in hospitalized patients: a meta-analysis of prospective studies. The Journal of American Medical Association 1998;279(15):1200-1205.

10. Jemal A, Ward E, Hao Y, Thun M. Trends in the leading causes of death in the United States. JAMA 2005;294(10):1255-1259.

11. Moura C, Acurcio F, Najara B. Drug-drug interactions associated with length of stay and cost of hospitalization. J Pharma Pharma Sci 2009;12(3):266-272. 